ARTICLE

\title{
Deazaflavin reductive photocatalysis involves excited semiquinone radicals
}

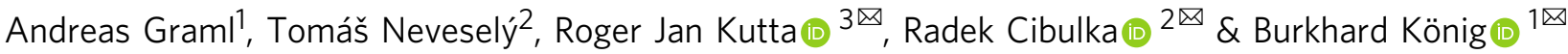

Flavin-mediated photocatalytic oxidations are established in synthetic chemistry. In contrast, their use in reductive chemistry is rare. Deazaflavins with a much lower reduction potential are even better suited for reductive chemistry rendering also deazaflavin semiquinones as strong reductants. However, no direct evidence exists for the involvement of these radical species in reductive processes. Here, we synthesise deazaflavins with different substituents at C5 and demonstrate their photocatalytic activity in the dehalogenation of $p$-halogenanisoles with best performance under basic conditions. Mechanistic investigations reveal a consecutive photo-induced electron transfer via the semiquinone form of the deazaflavin as part of a triplet-correlated radical pair after electron transfer from a sacrificial electron donor to the triplet state. A second electron transfer from the excited semiquinone to $p$-halogenanisoles triggers the final product formation. This study provides first evidence that the reductive power of excited deazaflavin semiquinones can be used in photocatalytic reductive chemistry.

\footnotetext{
${ }^{1}$ Institute of Organic Chemistry, University of Regensburg, 93040 Regensburg, Germany. ${ }^{2}$ Department of Organic Chemistry, University of Chemistry and Technology, Prague, 16628 Prague, Czech Republic. ${ }^{3}$ Institute of Physical and Theoretical Chemistry, University of Regensburg, 93040 Regensburg, Germany.

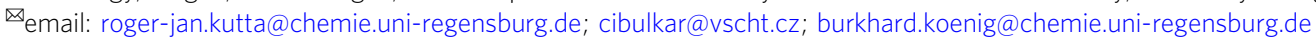


lavins, in the form of flavin mononucleotide (FMN) or flavin adenine dinucleotide (FAD), act as cofactors in various types of enzymes ${ }^{1,2}$. Some organisms also use deazaflavins ( $\mathrm{dFls} ; \mathrm{dF}_{0}$ or $\mathrm{dF}_{420}$, see Fig. 1a) where the $\mathrm{N}-5$ atom of the isoalloxazine ring is replaced by a carbon atom ${ }^{3,4}$. Despite their structural similarity, their roles in biological systems differ substantially ${ }^{3,5}$. Flavins (Fls) form semiquinones $\left(\mathrm{Fl}_{\mathrm{sq}} \mathrm{s}\right)$ (Fig. 1b), which are transiently stable in solution ${ }^{6}$ and more stable in protein environments ${ }^{7,8} . \mathrm{Fl}_{\mathrm{sq}} \mathrm{s}$ are typically involved in one-electron redox processes ${ }^{1,9}$. Fully reduced flavin $\left(\mathrm{Fl}_{\text {red }}\right)$ participates in two-electron reactions or, similarly as $\mathrm{Fl}_{\mathrm{sq}}$, interacts readily with molecular oxygen $\left(\mathrm{O}_{2}\right)$, forming reactive oxygen species (ROS) or flavin hydroperoxide $(\mathrm{FlOOH})^{10-13}$. $\mathrm{FlOOH}$ is the key agent in oxygenations mediated by flavindependent monooxygenases ${ }^{14,15}$. In contrast to Fls, dFls serve exclusively as two-electron carriers, thus behaving rather like nicotinamide adenine dinucleotide (phosphate) (NAD $(\mathrm{P}) \mathrm{H})^{3,5}$. Fully reduced deazaflavins $\left(\mathrm{dFl}_{\text {red }} \mathrm{s}\right)$ are considerably stable against oxidation by oxygen, thus avoiding formation of $\operatorname{ROS}^{10}$. This is one reason why dFls have been tested as native coenzyme (FAD or FMN) substitutes ${ }^{16-18}$.

Both Fls and dFls absorb visible light enabling their involvement in light-dependent processes ${ }^{19-22}$. Fl cofactors in their fully reduced form participate in photo-induced electron transfer (PET) reactions in DNA photolyases repairing pyrimidine dimers formed upon exposure to ultraviolet (UV) light ${ }^{23,24}$. Fls in their oxidised form are responsible for bacterial bioluminescence ${ }^{25}$ or perform various functions in photoreceptors ${ }^{7,26-28} \cdot \mathrm{dFl} \mathrm{dF}_{0}$ in its oxidised form serves as a light-harvesting antenna in photolyases $^{29}$. Inspired by nature, artificial Fl derivatives as well as flavoenzymes have been applied in photoredox catalysis and photobiocatalysis, mainly in oxidative transformations or in energy transfer processes $6,20,30-44$. Photoenzymatic radical polymerisation employing highly reducing excited $\mathrm{FADH}^{*-}$ known from photolyases is rare and a very recent example of a photoreductive process with $\mathrm{Fl}^{45}$. In the $\mathrm{dFl}$ series, $\mathrm{dFl}_{\text {red }}$ has been found to be generated from $\mathrm{dFl}$ by PET from ethylenediaminetetraacetic acid used as sacrificial reductant ${ }^{46}$. This procedure has been utilised in the $\mathrm{NAD}(\mathrm{P}) \mathrm{H}$-independent regeneration of $\mathrm{FADH}_{2}$ from $\mathrm{FAD}^{16,47}$.

$\mathrm{dFl}$ belong to the redox cofactors with the lowest redox potential; the first reduction potential of $\mathrm{dFl}\left[E\left(\mathrm{dFl} / \mathrm{dFl}_{\mathrm{sq}}\right)\right]$ is even more negative than that of Fls by $0.5 \mathrm{~V}^{3}$. Therefore, dFls are better suited for reductive chemistry than Fls. The very negative first reduction potential renders the $\mathrm{dFl}$ semiquinone $\left(\mathrm{dFl}_{\mathrm{sq}}\right)$ as a strong reducing agent. Despite this fact, there is no precedence of reductive processes involving this radical species. This might result from the very low stability of the $\mathrm{dFl}_{\mathrm{sq}}$ free in the solution $^{3,5,48}$.

Here we demonstrate that the reducing power of excited $\mathrm{dFl}$ radicals can be used in the presence of two substrates: (i) a sacrificial electron donor, e.g. diisopropyl(ethyl)amine (DIPEA), allowing the photochemical formation of the radical $\mathrm{dFl}_{\mathrm{sq}}$ and (ii) a substrate for reduction, $p$-halogenanisole, undergoing dehalogenation via the excited radical $\mathrm{dFl}_{\mathrm{sq}} *$.

\section{Results}

Design and synthesis. A series of 5-dFls 1-5 was synthesised with different substituents in position 5 (H-, Me-, $i \mathrm{Pr}-, \mathrm{CF}_{3^{-}}$, and $\left.\mathrm{Ph}-\right)$ via two different routes depending on the substituent (Fig. 2 and Supplementary Notes 1 and 2). Derivatives 1-4 were obtained following route A starting from 3,4-dimethoxyaniline (6). Reductive amination yielded compound 7 , which was subsequently coupled with 6-chloro-3-methylpyrimidine-2,4(1H,3H)dione to give access to the key intermediate 8 . Depending on the reaction conditions for the following step, the corresponding products 1-4 were obtained. As this synthetic method did not allow the synthesis of the phenyl derivative 5 , route $B$ was developed. In this three-component microwave-assisted procedure, adapted from $\mathrm{Tu}$ et al. ${ }^{49}$, compound $\mathbf{5}$ was obtained from a reaction of benzaldehyde with $N$-butyl-3,4-dimethoxyaniline (7) and $N$-methylbarbituric acid (9). Following this procedure, the phenyl derivative could be isolated in both the oxidised $\left(\mathbf{5}_{\mathrm{ox}}\right)$ and fully reduced form $\left(5_{\text {red }}\right)$, which reflects the low sensitivity of the<smiles>[Y4]C[C@H](O)[C@@H](O)[C@H](O)Cn1c2nc(=O)[nH]c(=O)c-2nc2cc(C)c(C)cc21</smiles>

$\mathrm{Fl}$

b Oxidised form (d) $\mathrm{F}$<smiles>[R7]c1cc2[Y]3c(=O)[nH]c(=O)nc3n([R9])c2cc1[2H]</smiles>
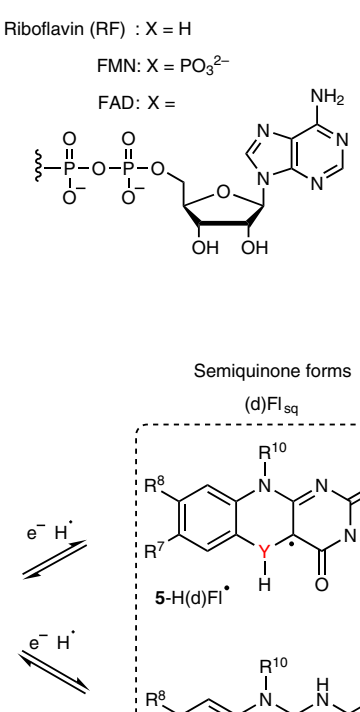

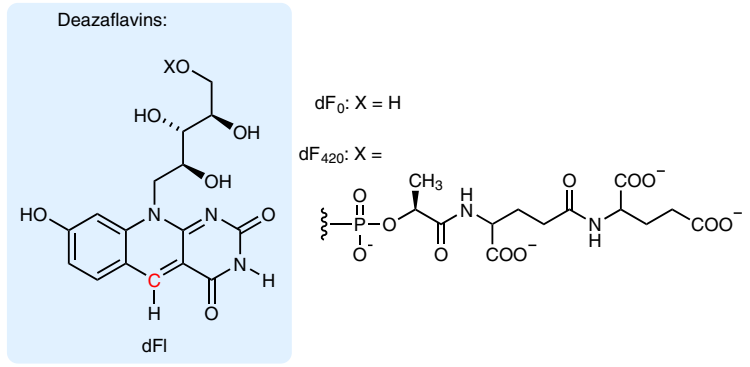

Fully reduced form (d) $\mathrm{FI}_{\text {red }}$
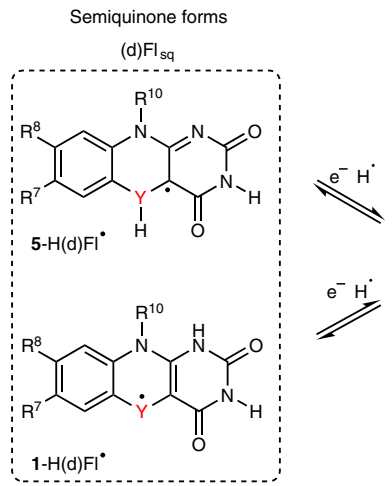<smiles>[R7]c1cc2c(cc1[2H])N([2H])c1[nH]c(=O)[nH]c1[Y]2[H]</smiles>

Fig. 1 Flavins, deazaflavins, and their redox forms. a Structure of flavin and deazaflavin cofactors. b Redox states of flavins and deazaflavins. In contrast to flavins, semiquinone deazaflavins are untypical intermediates in redox chemistry. 


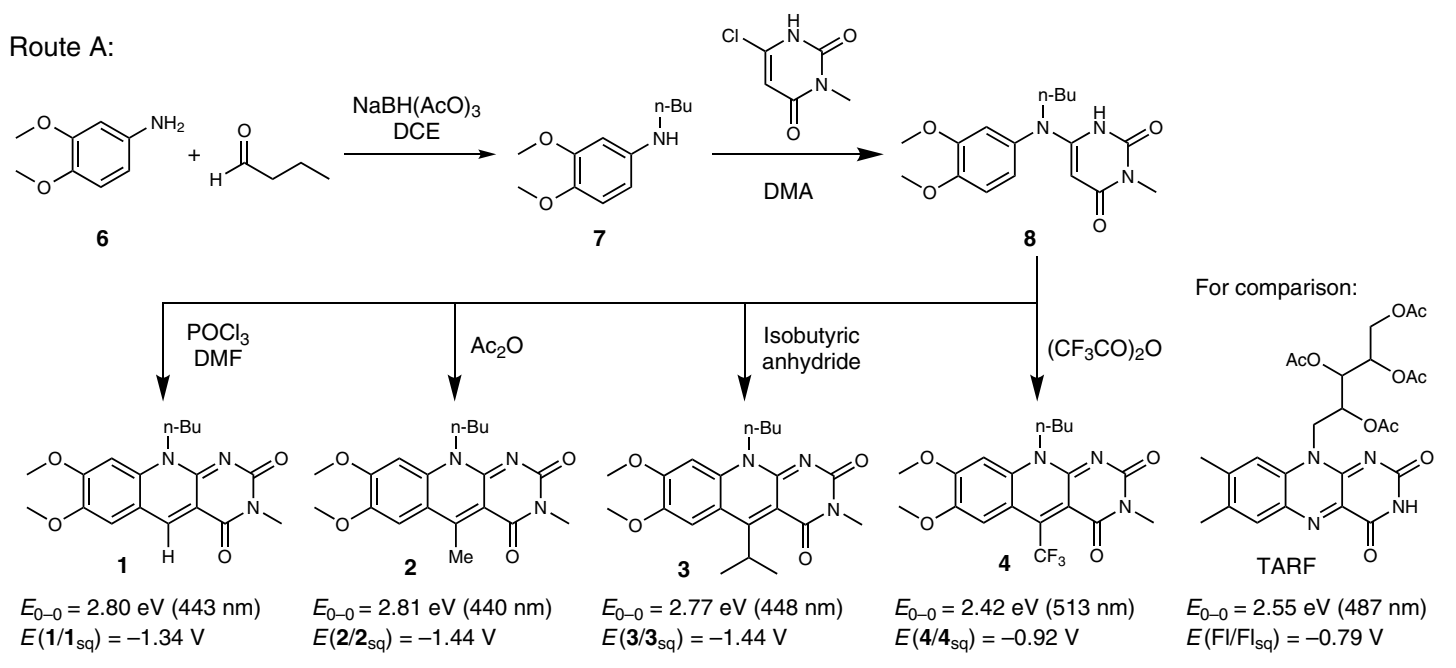

Route B:
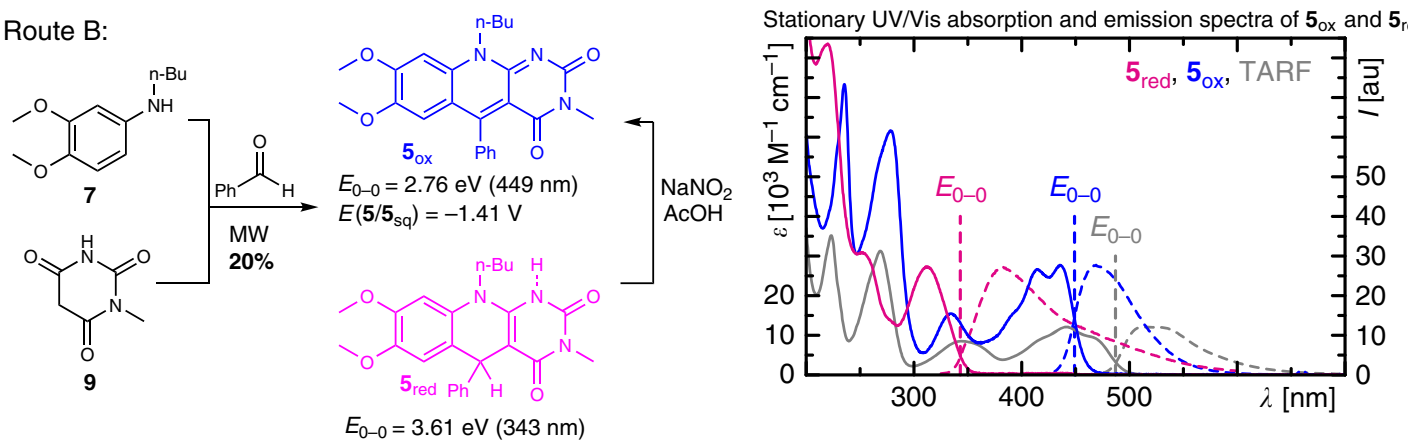

Fig. 2 Synthesis and spectral and electrochemical properties. Electronic transition energies, $E_{0-0,}$ and first reduction potentials vs. saturated calomel electrode (SCE) are given for all deazaflavins. Full spectra are shown for $\mathbf{5}_{\text {ox }}$ and $\mathbf{5}_{\text {red. }}$. Data for tetraacetyl riboflavin (TARF) are given for comparison. Further details on synthesis and characterisation are given in Supplementary Notes 1 and 2, respectively.

$\mathrm{dFl}_{\text {red }}$ against $\mathrm{O}_{2}{ }^{3,50}$. This observation is further supported by incubation of $\mathbf{5}_{\text {red }}$ in darkness for $19 \mathrm{~h}$ in non-degassed acetonitrile $(\mathrm{ACN})$ where no considerable formation of $\mathbf{5}_{\mathrm{ox}}$ is observed via absorption spectroscopy (Supplementary Note 3 ). However, light excitation of $\mathbf{5}_{\text {red }}$ allows to overcome the activation barrier for re-oxidation by $\mathrm{O}_{2}$ resulting in almost stoichiometric conversion to $\mathbf{5}_{\text {ox }}$ (Supplementary Note 3 ).

Photophysical and electrochemical characterisation. Compounds 1-3 have similar UV/visible (Vis) absorption and emission spectra in $\mathrm{ACN}$ giving similar electronic transition energies of these dFls with the usual blue-shift of around $40 \mathrm{~nm}$ compared to isoalloxazines (Fig. 2 and Supplementary Fig. 1) ${ }^{51}$. In contrast, derivative 4 with the strong electron withdrawing group $-\mathrm{CF}_{3}$ shows a red-shifted electronic transition by $26 \mathrm{~nm}$ in ACN compared to isoalloxazines. The compounds 1-4 are all highly emitting with fluorescence quantum yields ranging from $67 \%$ to $85 \%$ in ACN. Their emission lifetimes in ACN range between 6.8 and $11.1 \mathrm{~ns}$ (Supplementary Note 2). In agreement with literature reports ${ }^{4}$, cyclo-voltammetry $(\mathrm{CV})$ shows more negative redox potential of the first reduction step of the dFls compared to tetraacetyl riboflavin (TARF) $\left(E\left(\right.\right.$ TARF$\left./ \mathrm{TARF}_{\mathrm{sq}}\right)=-0.79 \mathrm{~V}$, ref. $\left.{ }^{39}\right)$ by $0.13-0.52 \mathrm{~V}$ (Supplementary Note 4 ).

The phenyl derivative $\mathbf{5}$ shows deviating characteristics compared to the other dFls. While the electronic transition energies are also blue-shifted compared to isoalloxazines and the redox potential of the first reduction step is also more negative compared to TARF, its emission properties are significantly different. The fluorescence quantum yield reaches only $16 \%$ and its excited singlet state lifetime is considerably reduced being only
1.7 ns (Supplementary Note 2). Furthermore, compound 5 is the only derivative that forms a thermally stable fully reduced form $\mathbf{5}_{\text {red }}$, which is only re-oxidised by light as discussed above (Supplementary Note 3).

Photodehalogenation. Owing to the strong reduction potential of $\mathrm{dFl}$ derivatives compared to their $\mathrm{Fl}$ analogues, we investigated their use in the reductive photoredox catalysis for the dehalogenation of aryl halides, which is considered as a benchmark reaction because of their very negative redox potentials. For instance, with a one-electron reduction potential of $-2.75 \mathrm{~V}^{52}, p$ bromoanisole ( $p$-BA) is beyond the limits of most organic photoredox catalysts ${ }^{53,54}$, or it requires combination of electrocatalysis and photocatalysis for dehalogenation ${ }^{55,56}$.

We achieved an almost quantitative yield of $p$-BA dehalogenation using the phenyl derivative $5(6 \mathrm{mM}, 8 \mathrm{~mol} \%$ relative to substrate), when irradiating at $385 \mathrm{~nm}$ in the presence of a sacrificial reducing agent, here we used DIPEA, and caesium carbonate $\left(\mathrm{Cs}_{2} \mathrm{CO}_{3}\right)$ (Table 1). The anisole yield is independent on the oxidation state of the photocatalyst, i.e. $\mathbf{5}_{\mathrm{ox}}$ or $\mathbf{5}_{\text {red }}$, since the $\mathrm{dFl}_{\text {red }} \mathbf{5}_{\text {red }}$ is re-oxidised by $\mathrm{O}_{2}$ and light as described above (Supplementary Note 3 ). Noteworthy, $\mathbf{5}_{\mathrm{ox}}$ also showed photodehalogenation of $p$-chloroanisole, whose redox potential is even more negative $\left(E_{\text {red }}=-2.88 \mathrm{~V}\right.$, ref. $\left.{ }^{52}\right)$.

We next investigated the influence of the solvent and the excitation wavelength on the total product yield (Supplementary Note 5). Interestingly, when dimethylformamide was used as solvent under otherwise identical conditions the product yield decreased by almost $50 \%$. With respect to the excitation wavelength, the best yield, ca. $80 \%$, was obtained for wavelengths 
Table 1 Photocatalytic dehalogenation of $p$-halogenanisole by deazaflavin $5_{o x}$ and $5_{\text {red- }}$

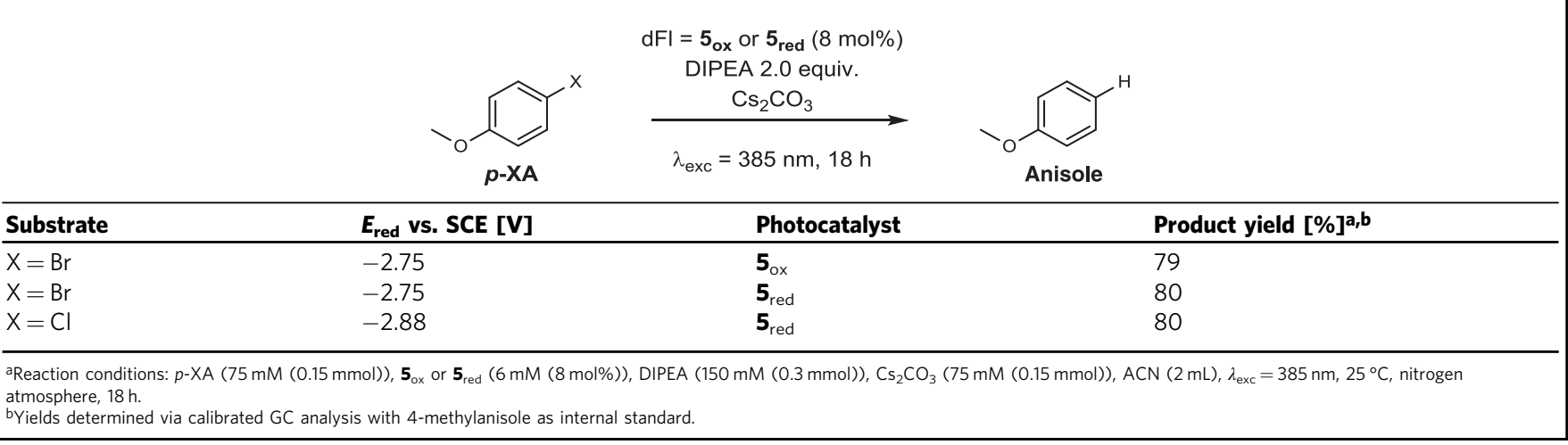

Table 2 Photocatalytic dehalogenation of $p$-bromoanisole by deazaflavin in dependence on the basicity.

\begin{tabular}{|c|c|c|c|c|c|c|}
\hline \multirow[b]{2}{*}{ Base } & \multicolumn{4}{|c|}{$\begin{array}{c}\text { dFI }(4 \mathrm{~mol} \%) \\
\text { DIPEA } 2.0 \text { equiv. } \\
\text { base }\end{array}$} & & \\
\hline & \multicolumn{6}{|c|}{ Product yield $[\%]^{a, b}$ using photocatalyst } \\
\hline None & 22 & 12 & 15 & 14 & 24 & 27 \\
\hline $\mathrm{NaHCO}_{3}$ & 20 & - & - & - & 22 & - \\
\hline $\mathrm{Cs}_{2} \mathrm{CO}_{3}$ & 19 & 38 & 67 & 15 & 60 & 64 \\
\hline $\mathrm{KO}^{t} \mathrm{Bu}$ & 50 & - & - & - & 59 & - \\
\hline
\end{tabular}

$\leq 400 \mathrm{~nm}$. When using light of $455 \mathrm{~nm}$, only $50 \%$ yield could be obtained. As a control, in the absence of photocatalyst, DIPEA, or irradiation, no reaction occurs. Recording the product build-up in case of $\mathbf{5}_{\text {ox }}$ showed that $60 \%$ conversion was observed already after $6 \mathrm{~h}$.

Furthermore, we investigated the effect of basicity on the dehalogenation efficiency of $p$-BA (Table 2). Without any base, only yields between $10 \%$ and $30 \%$ are observed for all photocatalysts. In the presence of $\mathrm{Cs}_{2} \mathrm{CO}_{3}$, under otherwise identical conditions, the yield was increased to $>60 \%$ for the dFls 3 and 5 , while the reactivity of dFls 1 and 4 remained unchanged or increased to only $38 \%$ for the methyl derivative 2 . For the dFls 1 and 5, we then tested bases with increasing basicity, i.e. $\mathrm{NaHCO}_{3}, \mathrm{Cs}_{2} \mathrm{CO}_{3}$, and $\mathrm{KO}^{t} \mathrm{Bu}$. While the activity of $\mathbf{5}$ was significantly enhanced by $\mathrm{Cs}_{2} \mathrm{CO}_{3}$ or $\mathrm{KO}^{t} \mathrm{Bu}$, the reactivity of 1 only increased in case of $\mathrm{KO}^{\mathrm{t}} \mathrm{Bu}$. These findings already indicate an important acidobasic equilibrium of a potential intermediate species of the photocatalyst that affects the overall performance. Thus a deprotonated form of one key intermediate seems to be beneficial (A more detailed discussion can be found in Supplementary Note 6).

Excited singlet state reaction results in a loss channel. The reactivity of the excited states of the compounds $\mathbf{1}$ and $\mathbf{5}_{\text {ox }}$ with the sacrificial substrate DIPEA was investigated by time-resolved absorption and emission spectroscopy in the absence of any additional base, since the main focus was on the understanding of the underlying photocatalytic reaction mechanism (Further studies on the role of specific deprotonation states is currently ongoing in our laboratories and will be presented elsewhere.). In both cases, the excited state quenching was observed without the formation of any additional transient species (Fig. 3 and Supplementary Note 7). This indicates the formation of a singlet born radical pair that recombines faster than it is formed owing to spin-allowed radical pair recombination (Fig. $3 \mathrm{e}$ and Supplementary Note 7). Such a fast recombination reaction was already observed in the Fl photo-oxidation of aromatic alcohols and represents a pure loss channel for photocatalytic applications ${ }^{6}$. In case of the reaction between DIPEA and the excited singlet of the $\mathrm{dFl}$, the bi-molecular reactions rates for $\mathbf{1}$ and $\mathbf{5}_{\mathrm{ox}}$ under low substrate concentrations $(<200 \mathrm{mM}$ DIPEA) are $(1.05 \pm 0.01) \times$ $10^{10} \mathrm{M}^{-1} \mathrm{~s}^{-1}$ and $(9.0 \pm 0.1) \times 10^{9} \mathrm{M}^{-1} \mathrm{~s}^{-1}$, respectively (see Stern-Volmer analysis in Supplementary Note 7). These values are smaller by $56 \%$ and $47 \%$, respectively, compared to the theoretical diffusion limited bi-molecular reaction limit (see Supplementary Note 7 for a detailed discussion), which might indicate a geometrical preference for reactive encounters allowing for necessary interactions, and thus enabling a high probability for the reaction to proceed.

In the presence of only the actual substrate $p$-BA (with a concentration of $100 \mathrm{mM}$, which is sufficiently high for diffusion controlled encounters with the excited singlet state of the photocatalyst), the transient absorption (TA) data of $\mathbf{1}$ and $\mathbf{5}_{\mathrm{ox}}$ resemble those of the photocatalysts alone demonstrating no reaction between $p$-BA and the corresponding excited states (Fig. $3 c$ and Supplementary Note 7). In addition, in case of the stable fully reduced form, $\boldsymbol{5}_{\text {red }}$, also no reaction between the 

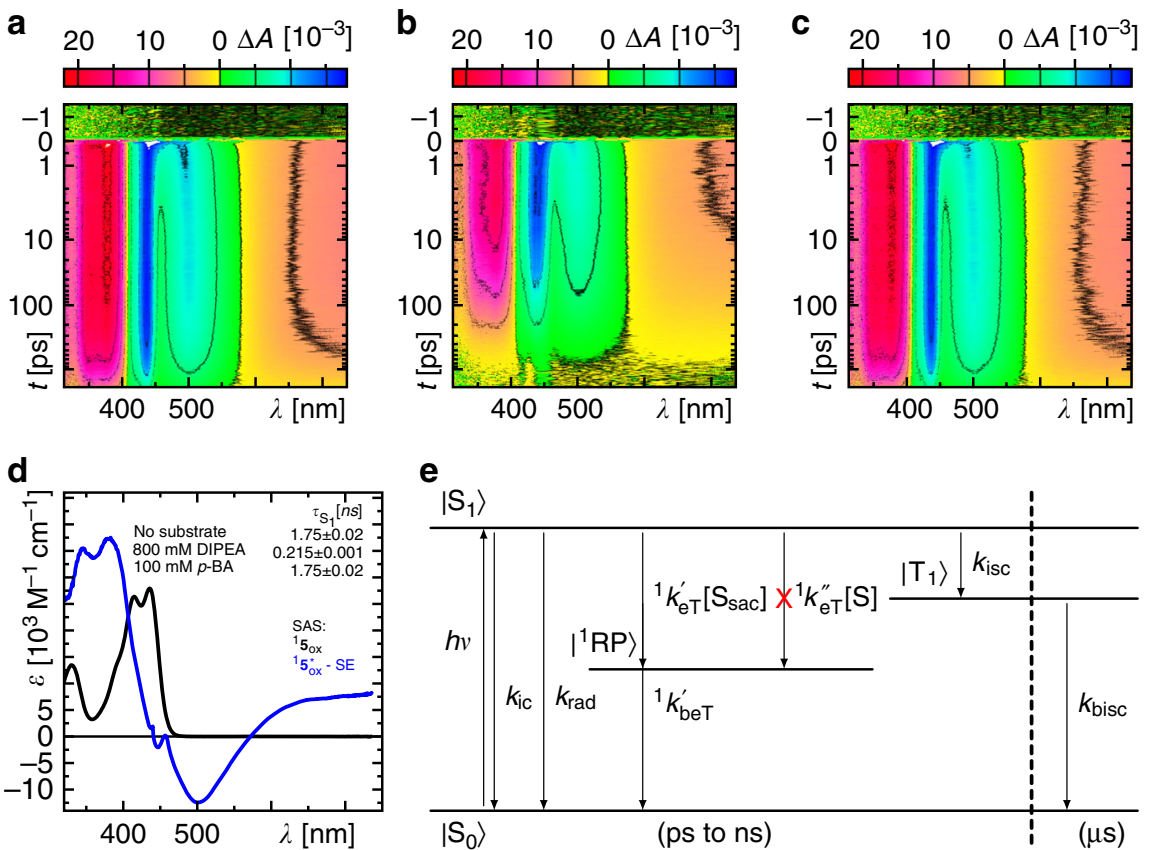

Fig. 3 Excited singlet state dynamics of $\mathbf{5}_{\mathbf{o x}} \mathbf{a}$ a-c False colour representation of the time-resolved absorption spectra of $\mathbf{5}_{\mathrm{ox}}(360 \mu \mathrm{M})$ in non-degassed ACN in the absence (a) or presence of either $800 \mathrm{mM} \mathrm{DIPEA} \mathrm{(b)} \mathrm{or} 100 \mathrm{mM} \mathrm{p}$-BA (c) exciting at $\lambda_{\text {exc }}=450$ nm. $\mathbf{d}$ Species-associated spectra (SAS) that contribute to the time-resolved absorption signals in a-c with excited singlet state lifetimes as indicated. e Model used to describe the time-resolved absorption data that results in physically reasonable SAS. On this time window, $k_{\text {isc }}$ is negligible, and since no further species spectrum is detectable, the assumption ${ }^{1} k_{\text {beT }}^{\prime} \gg^{1} k_{\text {eT }}^{\prime}\left[\mathrm{S}_{\text {sac }}\right]$ is justified. SE stimulated emission, rad radiative, ic internal conversion, (b)eT (back) electron transfer, (b)isc (back) intersystem crossing, $\mathrm{S}_{0}$ singlet ground state, $\mathrm{S}_{1}$ excited singlet state, $\mathrm{T}_{1}$ triplet state, ${ }^{1} \mathrm{RP}$ singlet born radical pair, $\mathrm{S}_{\text {sac }}$ sacrificial electron donor, $\mathrm{S}$ substrate.

excited singlet state and the substrate $p$-BA is observed (Supplementary Note 7).

Triplet state reaction forms transiently stable semiquinone. TA spectroscopy in the ns to $\mu$ s range was used in order to study the triplet state formation of $\mathbf{5}_{\text {ox }}$ (Fig. $4 \mathrm{a}$, e as well as further details in Supplementary Notes 2 and 8). In comparison to isoalloxazines, its yield is low being only ca. $11 \%$ (Supplementary Table 1 ). In the presence of the substrate $p$-BA $(50 \mathrm{mM})$, no reaction is observed with either the excited singlet or triplet state of $5_{\text {ox }}$ (Fig. $4 \mathrm{~b}$, e). In contrast, in the presence of the sacrificial electron donor DIPEA $(50 \mathrm{mM})$ electron transfer (eT) from DIPEA to the triplet state occurs forming the semiquinone $\mathbf{5}_{\mathrm{sq}}$ (Fig. $4 \mathrm{c}$, f), whose spectrum agrees well with the electrochemically generated spectrum (Fig. $5 \mathrm{~g}$ and Supplementary Note 9). The yield for eT can be determined from the corresponding decay rates to $\Phi_{\mathrm{eT}}=1-k_{0} k_{\mathrm{q}}^{-1}=87 \%$, where $k_{0}$ is the total decay rate constant of the triplet in the absence and $k_{\mathrm{q}}$ in the presence of DIPEA. Considering the concentration of DIPEA $(50 \mathrm{mM})$, the corresponding bi-molecular reaction rate with the triplet state is given to be $(8.7 \pm 0.1) \times 10^{8}$ $\mathrm{M}^{-1} \mathrm{~s}^{-1}\left(k_{\mathrm{eT}}=\Phi_{\mathrm{eT}} k_{\mathrm{q}}([\mathrm{DIPEA}])^{-1}\right)$. However, in the available spectral window of our experiment, we do not observe spectral signatures of the corresponding DIPEA radical cation. The assignment as the semiquinone radical is further proven by recording its electron paramagnetic resonance spectrum under photo-stationary conditions (Supplementary Note 10). In the presence of both $p$-BA and DIPEA, again, only the triplet reaction with DIPEA is observed, but no indication for a reaction between $p$-BA and $5_{\mathrm{sq}}$ is found (Fig. $4 \mathrm{~d}, \mathrm{f}$ ). In summary, while the excited singlet state reaction with DIPEA results in a singlet born spin correlated radical pair, ${ }^{1}\left[\mathbf{5}_{\mathrm{sq}}, \mathrm{DIPEA}^{\bullet+}\right]$, which recombines faster than it is formed owing to spin allowance, the triplet reaction with DIPEA involves a triplet born radical pair, ${ }^{3}\left[5_{\text {sq }}\right.$, DIPEA $\left.^{\bullet+}\right]$, which is spin forbidden for recombination, thus allowing its accumulation (Fig. 4g).

Reactivity of the excited $\mathbf{d F l}_{\text {sq. }}$. In the next step, we investigated the reactivity of $\mathbf{5}_{\mathrm{sq}}$ in its excited state $\mathbf{5}_{\mathrm{sq}}{ }^{*}$ towards the dehalogenation of $p$-BA. For this purpose, we generated the semiquinone form $\mathbf{5}_{\mathrm{sq}}$ electrochemically without the need of the lightinduced reaction with DIPEA by applying constantly $-1.2 \mathrm{~V}$ to the sample in ACN and followed its reactivity by UV/Vis absorption over time under the following four conditions: (1) alone in the dark, (2) in the dark and the presence of $p$-BA (250 $\mathrm{mM}),(3)$ alone in the light $\left(\lambda_{\text {exc }}=385 \mathrm{~nm}\right)$, and (4) in the light $\left(\lambda_{\text {exc }}=385 \mathrm{~nm}\right)$ and in the presence of $p$-BA $(250 \mathrm{mM})$. Alone in the dark, initially the concentration of $\mathbf{5}_{\text {ox }}$ depletes completely and $\mathbf{5}_{\mathrm{sq}}$ is formed simultaneously (Fig. 5a). On longer delays, the concentration of $5_{\mathrm{sq}}$ reduces by ca. $18 \%$ with the simultaneous formation of $\mathbf{5}_{\text {red }}$ indicating partial disproportionation of two $\mathbf{5}_{\mathrm{sq}}$ molecules into $\mathbf{5}_{\mathrm{ox}}$ and $\mathbf{5}_{\mathrm{red}}{ }^{19}$. The former does not recover considerably because the electrode-driven one electron reduction immediately forms $\mathbf{5}_{\text {sq. }}$. Using the species spectra obtained from the spectro-electrochemical experiment (Fig. $5 \mathrm{~g}$ and Supplementary Note 9), the sequence of spectra can be perfectly decomposed in order to obtain the corresponding concentration-time profiles of the contributing species (Fig. 5c). Repeating this experiment in the dark but now in the presence of $p$-BA, exactly the same behaviour is observed within the experimental error (Fig. 5b, c) demonstrating no reaction between $p$-BA and either of the $\mathrm{dFl}$ redox species in their ground states. This additionally confirms the results of the TA spectroscopy.

However, in the experiments with simultaneous illumination of the sample, significantly different kinetics are observed compared to the situation in the dark. In the absence of $p$-BA but presence of light, again, a rapid reduction of $\mathbf{5}_{\mathrm{ox}}$ is observed (Fig. $5 \mathrm{~d}$ ). 

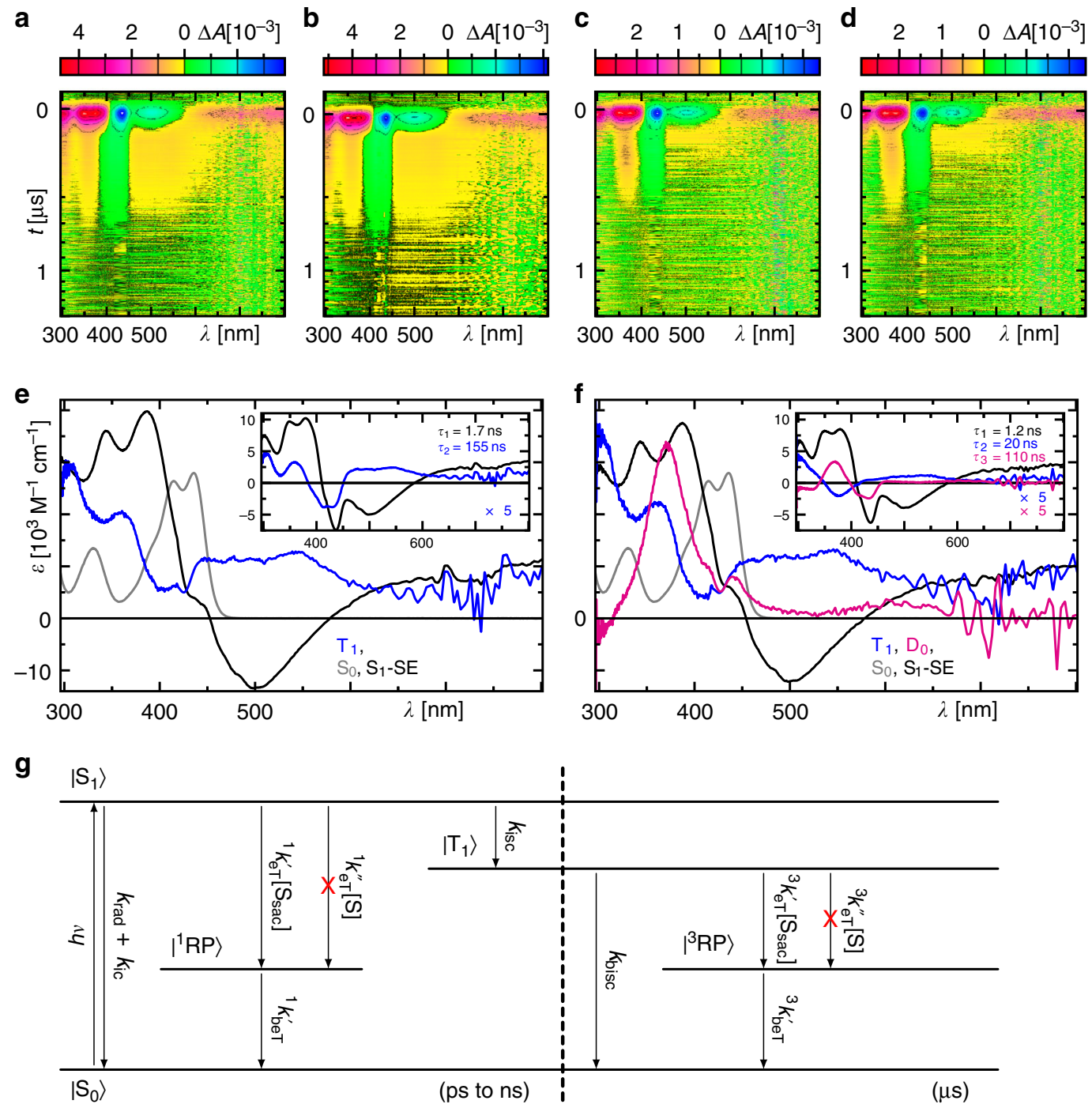

Fig. 4 Excited singlet and triplet state dynamics of $\mathbf{5}_{\text {ox }}$ - a-d False colour representation of the time-resolved absorption spectra of $\mathbf{5}_{\mathrm{ox}}(60 \mu \mathrm{M})$ in nondegassed ACN in the absence (a) or presence of either $50 \mathrm{mM} \mathrm{p}$-BA (b), $50 \mathrm{mM} \mathrm{DIPEA}(\mathbf{c})$, or both $50 \mathrm{mM}$-BA and $50 \mathrm{mM}$ DIPEA (d) exciting at $\lambda_{\text {exc }}=$ $430 \mathrm{~nm}$. e Species-associated spectra (SAS) that contribute to the time-resolved absorption signals in $\mathbf{a}-\mathbf{b}$, which were generated by applying the model in $\mathbf{g}$ to the decay-associated difference spectra (DADS) shown in the inset. $\mathbf{f}$ Same as e but for the data in $\mathbf{c}$, $\mathbf{d}$. SE stimulated emission, rad radiative, ic internal conversion, (b)eT (back) electron transfer, (b)isc (back) intersystem crossing, superscript 1/3 singlet or triplet state, RP spin correlated radical pair containing the $\mathbf{5}_{\mathrm{sq}}$ (D doublet state), $\mathrm{S}_{\mathrm{sac}}$ sacrificial electron donor, $\mathrm{S}$ substrate.

However, under these conditions $\mathbf{5}_{\text {sq }}$ does not accumulate to the same extent (here only to $75 \%$ in the transient maximum) as in the case without illumination. Instead, a significantly enhanced formation of $\mathbf{5}_{\text {red }}$ up to $70 \%$ in the transient maximum is observed, indicating a light-induced second eT from the electrode to the excited $\mathbf{5}_{\mathrm{sq}}{ }^{*}$. Again, these data can be decomposed well with the known species spectra of the three redox states of $\mathbf{5}$ (Fig. 5f). In the final experiment with light and $p$-BA, again, different kinetics are observed compared to the three experiments described before. In this case, $\mathbf{5}_{\text {ox }}$ is only converted to ca. $75 \%$. This is accompanied by a significantly reduced accumulation of $5_{\text {sq }}$ and $5_{\text {red }}$ (Fig. 5e), thus indicating a reaction between $p$-BA and $\mathbf{5}_{\mathrm{sq}}$ in its excited state reforming $\mathbf{5}_{\mathrm{ox}}$. Using only the known species-associated spectra (SAS) of the dFl intermediates, this time, the decomposition of the data shows significant deviations. Closer inspection of the arising absorption band at $300 \mathrm{~nm}$ reveals an asymmetric shape compared to the expected absorption band of $\mathbf{5}_{\text {red }}$ indicating some underlying spectral contributions of a different species than those already known from the
dFls. After subtraction of a fitted linear combination of the known spectral features of $\mathrm{dFl}$, an absorption spectrum with a single absorption band peaking at $330 \mathrm{~nm}$ remains (magenta spectrum in Fig. 5g). Considering a potential radical anion of $p$-BA as an intermediate arising after eT from excited $\mathbf{5}_{\mathrm{sq}} *$ to $p$-BA, we calculated the absorption spectrum of $p^{-B^{*-}}$ quantum chemically using a high level of theory, i.e. state-averaged XMCQDPTCASSCF $(12,12)$, considering also the solvent environment by the polarisable continuum model (PCM) for ACN (see Supplementary Note 11). As seen in Fig. $5 \mathrm{~g}$ and Supplementary Fig. 12a, the calculated spectrum matches the measured spectrum accurately, so that we assign this spectrum to $p-\mathrm{BA}^{{ }^{-}}$. Considering the $p$ - $\mathrm{BA}^{{ }^{-}}$ spectrum together with the already determined species spectra for all $\mathrm{dFl}$ intermediates now results in a good fit with deviation within the experimental error. Since the fit does not depend on the scaling of the $p^{-B^{*-}}$ spectrum, we scaled the spectrum arbitrarily so that the resulting concentration-time profile stays below all Fl contributions. Furthermore, the quantum chemical calculation revealed a significantly longer bond length between 

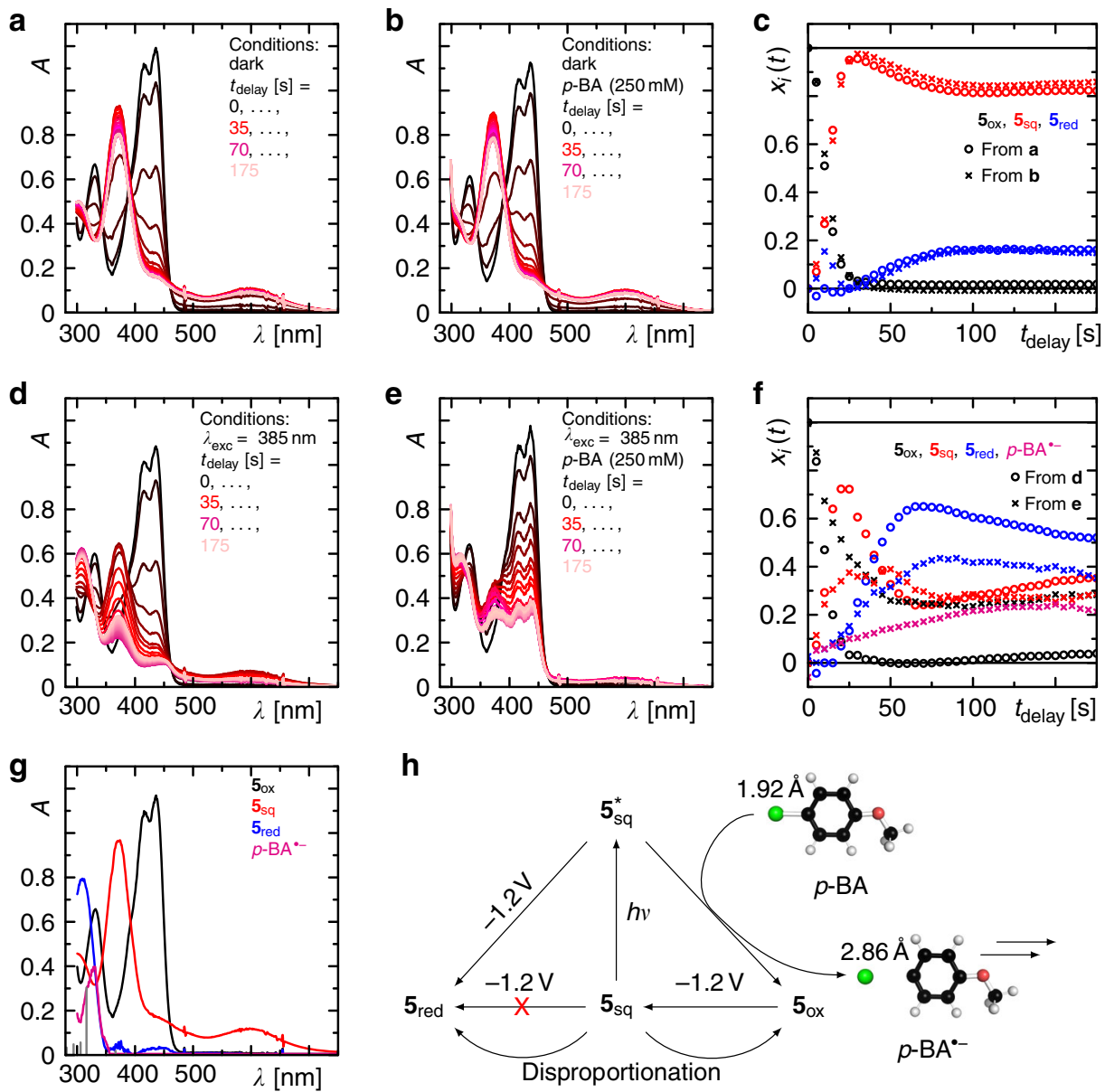

Fig. 5 Reactivity of electrochemically formed semiquinone $\mathbf{5}_{\mathbf{s q}} \mathbf{a}, \mathbf{b}, \mathbf{d}, \mathbf{e}$ Sequences of UV/Vis absorption spectra after application of $-1.2 \vee$ to the sample at conditions as indicated. $\mathbf{c}$, $\mathbf{f}$ Concentration-time profiles from fitting the species spectra shown in $\mathbf{g}$ to the data as indicated. The grey vertical lines in $\mathbf{g}$ correspond to the quantum chemically calculated stick spectrum of $p$-BA ${ }^{\bullet-}$ as described in the text. $\mathbf{h}$ Summary of all the observed processes. The stick and ball structure of $p$-BA and $p-\mathrm{BA}^{\bullet-}$ are the result of quantum chemical calculations as described in the main text and Supplementary Note 11. The significantly reduced $\mathrm{Br}^{-}$dissociation energy in $p$ - $\mathrm{BA} A^{\bullet-}$ demonstrates the final bromine dissociation upon one electron reduction.

the bromine and the adjacent carbon atom in $p$-BA $^{--}(2.86 \AA)$ than in $p$-BA $(1.92 \AA)$ as well as a significantly reduced dissociation energy being close to thermal energy fluctuations (Supplementary Fig. 12b), which explains well the observed final dissociation of the bromine during the dehalogenation, which is triggered by a single electron reduction step as summarised in Fig. 5h (Further details are given in Supplementary Note 11.).

Analogous experiments were conducted with the nonsubstituted dFl $\mathbf{1}$. However, in contrast to the experiments with 5 , the semi-reduced form could not be observed on the time scale of the measurements. The failure of detecting the semi-reduced form $\mathbf{1}_{\mathrm{sq}}$ indicates that its lifetime is significantly shorter compared to that of $\mathbf{5}_{\mathrm{sq}}$. This agrees with the observation of a significantly lower yield in the dehalogenation using 1 compared to $\mathbf{5}$, since less $\mathbf{1}_{\mathrm{sq}}$ may be accumulated.

Photocatalytic reaction mechanism based on consecutive PET (conPET). In summary, our results can be compiled to the photocatalytic reaction mechanism depicted in Fig. 6. With respect to the redox potential neither $\mathbf{5}_{\text {red }}\left(E\left(5_{\mathrm{sq}} / \mathbf{5}_{\mathrm{red}}\right)=-1.6 \mathrm{~V}\right)$ nor $5_{\mathrm{sq}}\left(E\left(\mathbf{5}_{\mathrm{ox}} / 5_{\mathrm{sq}}\right)=-1.41 \mathrm{~V}\right)$ can reduce $p$-BA $\left(E_{\text {red }}=-2.75 \mathrm{~V}\right)$ in their ground states. The participation of the excited fully reduced form $\mathbf{5}_{\text {red }} *$ is not observed most likely due to very efficient intrinsic deactivation of the excitation energy as seen in fast deactivation kinetics on a ps time scale (Supplementary Note 7 and Supplementary Fig. 8). In the presence of a sacrificial electron donor DIPEA, we observe different reactivities for either the excited singlet or triplet state of $\mathbf{5}_{\mathrm{ox}}$. In the excited singlet state reaction, a singlet born spin correlated radical pair, ${ }^{1}\left[\mathbf{5}_{\mathrm{sq}}\right.$, DIPEA $^{*}$ ], is formed, which recombines faster than it is formed. Accordingly, this reaction represents a pure loss channel. In contrast, eT to the triplet state results in a triplet born radical pair, ${ }^{3}\left[\mathbf{5}_{\mathrm{sq}}, \mathrm{DIPEA}^{\bullet+}\right]$, that is spin forbidden for recombination, thus allowing the accumulation of the considerably stable $\mathbf{5}_{\mathrm{sq}}$. As a consequence, $\mathbf{5}_{\mathrm{sq}}$ can be excited by a second photon $\left(E^{*}\left(\mathbf{5}_{\mathrm{ox}} / \mathbf{5}_{\mathrm{sq}}\right)\right.$ $=-3.3 \mathrm{~V}$ ), which enables a conPET ${ }^{57}$ from $\mathbf{5}_{\mathrm{sq}}{ }^{*}$ to the substrate, $p$-BA, regenerating $\mathbf{5}_{\mathrm{ox}}$ in its ground state and closing the photocatalytic cycle. The dissociation energy for the bond between the bromine and the adjacent carbon in $p$ - $\mathrm{BA}^{*-}$ is significantly reduced leading to thermally driven dissociation into $\mathrm{Br}^{-}$and the aryl radical. Finally, anisole is formed via hydrogen abstraction from either a DIPEA radical cation or a solvent molecule ${ }^{57}$. Owing to the lack of the observation of any protonated $\mathbf{5}_{\mathrm{sq}}$ form (see Supplementary Note 6 ), the radical anion of $5_{\mathrm{sq}}$ is the active species.

\section{Discussion}

We have described the detailed photocatalytic mechanism of a reductive dehalogenation of $p$-halogenanisole by dFls. The key point is the conPET via the anionic semiquinone form of the dFI. 


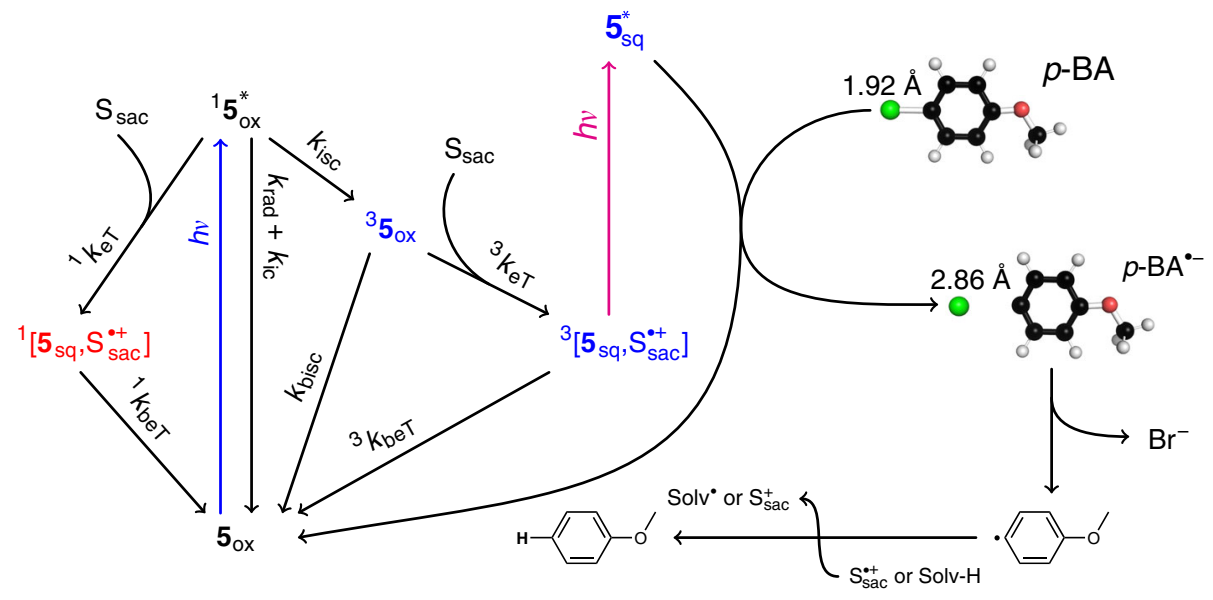

Fig. 6 Photocatalytic reaction mechanism. A sacrificial electron donor, e.g. DIPEA, reacts either with the excited singlet or triplet state of the deazaflavin. In the excited singlet state reaction, a singlet born spin correlated radical pair, ${ }^{1}\left[\mathbf{5}_{\mathrm{sq}}, \mathrm{S}_{\mathrm{sac}}^{*+}\right]$, is formed after eT. This radical pair recombines faster than it is formed. In contrast, eT to the triplet state results in a triplet born radical pair, ${ }^{3}\left[\mathbf{5}_{\mathrm{sq}}, \mathrm{S}_{\mathrm{sac}}^{+}\right]$, allowing the accumulation of the considerably stable $\mathbf{5}_{\mathrm{sq}} . \mathbf{5}_{\mathrm{sq}}$ can be excited by a second photon enabling a consecutive photo-induced electron transfer from $\mathbf{5}_{\mathrm{sq}}{ }^{*}$ to the substrate, $p$-BA, regenerating $\mathbf{5}_{\mathrm{ox}}$ in its ground state and closing the photocatalytic cycle. Finally, anisole is formed via hydrogen abstraction from either a $\mathrm{S}_{\mathrm{sac}}^{*+}$ or a solvent molecule.

In doing so, we have revealed that dFls are valuable photocatalysts for reductive chemistry. In summary, after photoexcitation of $\mathrm{dFl}$ followed by intersystem crossing a sacrificial electron donor, at a moderate concentration, will enable a first eT to the triplet state resulting in a considerably stable anionic semiquinone. Additional excitation of the anionic semiquinone provides sufficient energy for a second eT process from the semiquinone to compounds with highly negative redox potentials, such as $p$-halogenanisoles. Finally, downstream reactions resulting in product formation occur spontaneously.

The action spectrum of the conPET reaction comprises the absorption of two different coloured photons by the two key photocatalytic forms of $\mathrm{dFl}$, where one is formed from the other having a distinct lifetime in the ns regime. Therefore, a concrete timed illumination of the photocatalytic system with short and intense pulses at the appropriate excitation wavelengths, which are temporally optimised to the lifetime of the key intermediates, should allow further improvement on the efficiency. This aspect is of general importance for all conPET-type reactions and should be addressed in future work.

To our knowledge, this study shows for the first time that the reductive power of excited $\mathrm{dFl}_{\mathrm{sq}}$ can be used in photocatalytic reductive chemistry. Moreover, because of its very negative potential, this species seems to belong to the most powerful reductants ${ }^{53,55,56,58-61}$. Therefore, this study expands the photocatalytic toolbox for new chemical transformations and should serve as a guide for engineering photocatalysts of the next generation.

\section{Methods}

Materials. Starting materials and reagents were purchased from commercial suppliers (Sigma Aldrich, Alfa Aesar, Acros, Fluka, VWR, or Fluorochem) and were used without further purification. Solvents were used as p.a. grade or dried and distilled according to literature known procedures.

Nuclear magnetic resonance (NMR) spectroscopy. NMR spectra were recorded at room temperature using a Bruker Avance $300\left(300 \mathrm{MHz}\right.$ for ${ }^{1} \mathrm{H}, 75 \mathrm{MHz}$ for $\left.{ }^{13} \mathrm{C}\right)$, a Bruker Avance $400\left(400 \mathrm{MHz}\right.$ for ${ }^{1} \mathrm{H}, 101 \mathrm{MHz}$ for $\left.{ }^{13} \mathrm{C}\right)$, an Agilent 400 MR DDR2 (400 MHz for ${ }^{1} \mathrm{H}$ and $101 \mathrm{MHz}$ for ${ }^{13} \mathrm{C}$ ), or a Varian Mercury Plus 300 $\left(300 \mathrm{MHz}\right.$ for ${ }^{1} \mathrm{H}, 75 \mathrm{MHz}$ for ${ }^{13} \mathrm{C}$ ) with internal solvent signal as reference. All chemical shifts are reported in $\delta$-scale as parts per million (multiplicity, coupling constant $J$, number of protons) relative to the solvent residual peaks as the internal standard (IS). NMR spectra are available in Supplementary Figs. 13-22.
Mass spectrometry. The mass spectrometric measurements were performed at the Central Analytical Laboratory of the University of Regensburg or at the Central Analytical Laboratory of UCT, Prague on a Finnigan MAT 95, ThermoQuest Finnigan TSQ 7000, Finnigan MATSSQ 710A, Agilent Q-TOF 6540 UHD, or a LTQ Orbitrap Velos (Thermo Fisher Scientific).

Gas chromatography (GC). GC measurements were performed on a GC 7890 from Agilent Technologies. Data acquisition and evaluation was done with Agilen ChemStation Rev.C.01.04. A capillary column HP-5MS/30 m $\times 0.25 \mathrm{~mm} / 0.25 \mu \mathrm{M}$ film and helium as carrier gas (flow rate of $1 \mathrm{~mL} / \mathrm{min}$ ) were used. The injector temperature (split injection: $40: 1$ split) was $280^{\circ} \mathrm{C}$, detection temperature $300^{\circ} \mathrm{C}$ (FID). The GC oven temperature programme was adjusted as follows: the initial temperature of $40^{\circ} \mathrm{C}$ was kept for 3 min and was increased at a rate of $15^{\circ} \mathrm{C} / \mathrm{min}$ until the injection temperature of $280^{\circ} \mathrm{C}$ was reached. After $5 \mathrm{~min}$, the temperature was further increased at a rate of $25^{\circ} \mathrm{C} / \mathrm{min}$ until the final temperature of $300{ }^{\circ} \mathrm{C}$ was reached and kept for $5 \mathrm{~min}$. Using 4-methylanisole as an IS, we obtained the GC calibration given in Supplementary Fig. 23 for the quantitative analysis.

Cyclo-voltammetry. CV measurements were performed with the three-electrode potentiostat galvanostat (PGSTAT302N, Metrohm Autolab). The control of the measurement instrument, the acquisition, and processing of the $\mathrm{CV}$ data were performed with the software Metrohm Autolab NOVA 1.10.4. Electrochemical studies were carried out under argon atmosphere in ACN containing $0.1 \mathrm{M}$ tetra$\mathrm{N}$-butylammonium hexafluorophosphate using ferrocene/ferrocenium $\left(\mathrm{Fc} / \mathrm{Fc}^{+}\right)$as an internal reference. A glassy carbon electrode (working electrode), platinum wire counter electrode, and Ag quasi-reference electrode were employed.

Spectro-electrochemistry. Measurements were performed in an Ottle Cell (Optically transparent thin-layer electro-chemical cell), pathlength $=0.02 \mathrm{~cm}$, working electrode: Pt minigrid, counter electrode: Pt minigrid, pseudo reference electrode: Ag wire. Samples were prepared by degassing a solution of $\mathbf{5}_{\mathrm{ox}}$ in ACN ( $3 \mathrm{mM}$ ) via bubbling of Argon for several minutes. The substrate, $p$-BA, was added via a Hamilton syringe resulting in a solution of $250 \mathrm{mM}$. A constant electric field of $-1.2 \mathrm{~V}$ was applied to the cell, and UV/Vis absorption spectra were recorded every $5 \mathrm{~s}$ (using an Agilent 8453 spectrometer). Irradiation was done via a handheld LED $\left(\lambda_{\max }=385 \mathrm{~nm}\right)$ for a time of ca. $2 \mathrm{~s}$ in between each spectrum. Spectroelectrochemical data are given in Fig. 5 and Supplementary Note 9.

General irradiation conditions. Samples were irradiated at $254 \mathrm{~nm}$ (UV handlamp from Herolab GmbH Laborgeräte, $254 \mathrm{~nm}, 8 \mathrm{~W}$ ), at $365 \mathrm{~nm}$ (UV handlamp from Herolab GmbH Laborgeräte, $365 \mathrm{~nm}, 8 \mathrm{~W}$ ), at $370 \mathrm{~nm}$ (Opulent Starboard, Luminus SST-10-UV-A130, $\lambda_{\max }=370 \mathrm{~nm}, I_{\text {typ }}=500 \mathrm{~mA}, I_{\max }=1.0 \mathrm{~A}, \Phi_{\text {typ }}=$ $875 \mathrm{~mW}$ ), at $385 \mathrm{~nm}$ (Opulent Starboard, Luminus SST-10-UV-A130, $\lambda_{\max }=$ $\left.385 \mathrm{~nm}, I_{\text {typ }}=500 \mathrm{~mA}, I_{\max }=1.5 \mathrm{~A}, \Phi_{\text {typ }}=1015 \mathrm{~mW}\right)$, or at $455 \mathrm{~nm}(\mathrm{CREE}$ XLamp Me-C LED, $\lambda_{\max }=455 \mathrm{~nm}, I_{\max }=700 \mathrm{~mA}$ ). The corresponding emission spectra of each LED are given in Supplementary Fig. 24 or in the corresponding figures containing sequences of UV/Vis absorption spectra.

Stationary UV/Vis absorption and emission spectroscopy. UV/Vis absorption (Cary 60 or Cary 100 UV-Vis spectrophotometer; Agilent) and UV/Vis emission 
spectra (Horiba FluoroMax-4 spectrofluorometer) were recorded at room temperature. Fluorescence quantum yields were determined with a Hamamatsu C9920-02 system equipped with a Spectralon integrating sphere. The quantum yield accuracy is $<10 \%$ according to the manufacturer.

Stepwise illumination and recording of absorption spectra. Stationary UV/Vis absorption spectra were recorded using an Agilent Cary 50 UV/Vis spectrophotometer in a sample cell of $10 \times 10 \mathrm{~mm}$ that can be flanged to the freeze pump and thaw apparatus and closed after degassing. A sample of $\mathbf{5}_{\text {red }}$ was illuminated using an UV handlamp (UV handlamp from Herolab GmbH Laborgeräte, $254 \mathrm{~nm}$, $365 \mathrm{~nm}, 8 \mathrm{~W}$ ) providing either 254 or $365 \mathrm{~nm}$. Continuous light was delivered onto the sample that was reproducibly positioned in ca. $2 \mathrm{~cm}$ distance without any further optics allowing for direct comparison of data sets recorded under different sample preparation conditions. After each illumination period, an absorption spectrum was recorded directly afterwards. The sample volume of $3 \mathrm{~mL}$ was continuously stirred during the illumination periods providing a homogeneously illuminated sample.

Time-resolved UV/Vis emission spectroscopy. A self-constructed time correlated single photon counting set-up ${ }^{62}$ was used to record emission decay data at single detection wavelength. A quartz cuvette with four optical windows of the dimension $2 \mathrm{~mm} \times 10 \mathrm{~mm}$ was used. The sample was excited along the $2 \mathrm{~mm}$ pathlength, and the emission was recorded orthogonally to this. The optical density of the sample was set to ca. 0.1 at the excitation wavelength over $2 \mathrm{~mm}$ pathlength.

Ns to ms time-resolved UV/Vis absorption spectroscopy. The streak camera set-up described first in refs. ${ }^{62,63}$ was adapted as follows. The third harmonic of a Nd:YAG laser $(10 \mathrm{~Hz}$, Surelite II, Continuum) pumping an Optical Parametric Oscillator (OPO, Continuum) tuned to $450 \mathrm{~nm}(10 \mathrm{~mJ}$, ca. $10 \mathrm{~ns})$ was used for sample excitation. As a probe light, a pulsed $150 \mathrm{~W}$ Xe-flash lamp (Applied Photophysics) was used that was focussed three times via toric mirror optics: (i) before probe shutter, (ii) into sample, and (iii) into spectrograph. The entire white light probe pulse was analysed by a combination of a spectrograph (200is, Bruker) and a streak camera (C7700, Hamamatsu Photonics). The use of mechanical shutters enabled the recording of a sequence of three individual data sets: (i) an image $\left(D_{\mathrm{FL}}\right)$ with both flash lamp and laser, (ii) an image $\left(D_{0}\right)$ without any incoming light, and (iii) an image $\left(D_{\mathrm{F}}\right)$ only with the flash lamp. One hundred such sequences were recorded, and corresponding data sets were averaged. Then the TA was calculated as:

$$
\Delta \mathrm{OD}=\log \left(\frac{D_{\mathrm{F}}-D_{0}}{D_{\mathrm{FL}}-D_{0}}\right) .
$$

A 10-mL sample was stepwise cycled by a peristaltic pump (ecoline, ISMATEC) through a flow cell with a pathlength of $2 \mathrm{~mm}$ for pump and $10 \mathrm{~mm}$ for probe beams (dimensions: $2 \mathrm{~mm} \times 10 \mathrm{~mm} \times 30 \mathrm{~mm}$, Starna) ensuring a total replacement of the sample prior to each individual measurement. No photocatalyst degradation was observed under the used conditions.

\section{Sub-ps and sub-ns pump/supercontinuum probe spectroscopy. Ultrafast} broadband TA experiments were carried out using UV/Vis pump-supercontinuum probe spectroscopy at $1 \mathrm{kHz}$ repetition frequency. In short, a Ti-sapphire amplifier system (Coherent Libra) was used to generate $800 \mathrm{~nm}$ with $1.2 \mathrm{~mJ}$ pulses at $1 \mathrm{kHz}$. The output was split into three parts of which only two were used: (1) Ca. $50 \%$ of the $800 \mathrm{~nm}$ pulses were used to pump a collinear Optical Parametric Amplifier (OPA, TOPAS-800-fs, Light Conversion) tuned to pump pulses centred at ca. $450 \mathrm{~nm}$ (ca. $100 \mathrm{fs}, \mathrm{ca} .400 \mathrm{~nJ}$ at the sample position) for sample excitation. (2) Ca. $10 \%$ were used to pump a non-colinear OPA (in-house build) tuned to pulses centred at ca. $530 \mathrm{~nm}$ (ca. $100 \mathrm{fs}$, ca. $5 \mu \mathrm{J}$ at the $\mathrm{CaF}_{2}$ position) for generation of supercontinuum white light probe pulses by focussing into a moving $\mathrm{CaF}_{2}$ disc of $1-\mathrm{mm}$ thickness giving a probe spectrum ranging from 310 to $700 \mathrm{~nm}$. Pump pulses were delayed via a motorised delay line equipped with an open corner cube mirror up to $2 \mathrm{~ns}$. Two complementary high-speed spectrographs (Entwicklungsbüro EB Stresing) for signal and reference recording were used. The pump and probe pulses were focussed colinearly into the sample to spot sizes of ca. 80 and 60 $\mu \mathrm{m}$ full width at half maximum, respectively. For longer delays reaching out from ns to $\mu$ s time ranges, a similar spectrometer was used in which the pump laser was electronically delayed relative to the probe laser. A detailed description can be found in ref. ${ }^{64}$. The relative polarisations between the pump and probe were set by a half-wave plate in the pump beam path to magic angle $\left(54.71^{\circ}\right)$ for observations of pure population changes or to either parallel $\left(0^{\circ}\right)$ or orthogonal $\left(90^{\circ}\right)$ for observation of the anisotropy. The averaged pre- $t_{0}$ laser scatter signal was subtracted from the data and the ca. 1 ps chirp of the white light was corrected for prior to data analysis using the coherent artefact as an indicator for time zero at each wavelength. Throughout the probe range, the spectral resolution was better than $4 \mathrm{~nm}$ and the temporal resolution was better than $150 \mathrm{fs}$. Ten individual scans with averaging 100 spectra per time point were typically recorded. The time axiswithin total 500 points-was linear between -1 and $2 \mathrm{ps}$ and logarithmic from $2 \mathrm{ps}$ to the maximum time delay ensuring that the dynamics on every time scale will have equal weighting in the fitting analysis. In the sub-ps TA set-up, $10 \mathrm{~mL}$ of the sample were cycled through an in-house build cell with a pathlength of $100 \mu \mathrm{m}$ for pump and probe beams. In sub-ns TA set-up, $10 \mathrm{~mL}$ of the sample were cycled through a flow cell (Starna) with a pathlength of $2 \mathrm{~mm}$ for pump and probe beams. In all cases, all scans resulted in reproducible data sets. In addition, the integrity of the sample was checked by recording stationary absorption spectra before and after each measurement. No photocatalyst degradation was observed under the used conditions. The shown data correspond to one representative measurement. No smoothing or filtering procedures were applied to the data.

TA data analysis and modelling. Singular value decomposition (SVD)-based rank analysis and global fitting were performed using an in-house written programme described previously ${ }^{62,63}$. In brief, the linear least squares problem

$$
\chi^{2}=\|\mathbf{\Delta A}-\mathbf{F B}\|^{2}=\text { Min }
$$

is solved, where $\Delta \mathbf{A}$ is the time-resolved absorption data matrix, $\mathbf{F}$ is the matrix containing the analytical functions accounting for the temporal changes in the data, i.e. exponential decays (convoluted with the instrument response, typically a Gaussian function), and $\mathbf{B}$ is the matrix with the to be determined spectra. Further optimisation of $\chi^{2}$ is achieved by optimising the rate constants in $\mathbf{F}$ by a nonlinear least squares algorithm. As a result of such fits, the so-called decayassociated difference spectra (in matrix B) and their associated optimised rate constants are obtained. These are the unique result of the global fit, and this treatment does not require any model for the kinetics involved in the transient processes. The number of exponentials in the global fit is determined by the SVD-based rank analysis, which is described elsewhere ${ }^{65}$. The model that relates the actual species kinetics to the elementary function is applied afterwards resulting in SAS. The shape of the SAS in terms of identity with well-known spectra or following physical laws decides about the appropriateness of the model. This step does not change the $\chi^{2}$ value found in the global fit, and therefore, this procedure has the advantage that all interpretation is performed with the same quality of fit.

As an alternative analysis, known species spectra, taken either from literature or recorded in this work, were taken in order to decompose the recorded timeresolved data matrix using the transpose of the data matrix and using the basis spectra instead of analytical functions. The resulting concentration-time profiles inform about the appropriateness of the basis spectra and the physical reasonability, i.e. total sum of species being constant to 1 .

Quantum chemical calculations. Quantum chemical calculations on all molecular moieties were performed using either the Firefly QC package ${ }^{66}$, which is partially based on the GAMESS (US) ${ }^{67}$ source code, or the Orca package ${ }^{68,69}$. All ground state structures were optimised on the level of restricted open shell density functional theory (ROHF-DFT) using the B3LYP functional and the aug-cc-pDVZ basis set. Complete active space self-consistency field (CASSCF) theory was used in order to calculate the static correlation energy. The highest 12 contributing $\pi$ and $n$ electrons were included into the CAS, distributed over 12 molecular orbitals (MO), and energy averaging over 10 states with equal weights, i.e. CASSCF $(12,12) 10$, was performed. In order to calculate the dynamic correlation energy, extended multiconfiguration quasi-degenerate perturbation theory (XMCQDPT) was used on top of the CASSCF optimised MOs ${ }^{70}$. In all cases, an intruder state avoidance denominator shift of 0.02 was used. The absorption spectrum for $\mathbf{5}_{\mathrm{sq}}$ was calculated via unrestricted open shell time-dependent DFT (TD-DFT) with the aug-cc-pDVZ basis set. Solvent effects were taken into account with the conductor-like PCM for the TD-DFT calculation and with the PCM for the XMCQDPT-CASSCF calculations. Relaxed potential energy surfaces along the $\mathrm{C}-\mathrm{Br}$ bond in $p-\mathrm{BA}$ and $p-\mathrm{BA} \cdot$ were performed on the DFT (B3LYP) level of theory with the aug-cc-pVDZ basis set.

\section{Data availability}

The authors declare that the data supporting the findings of this study are available within the paper and Supplementary Information, as well as from the authors upon reasonable request.

Received: 16 March 2020; Accepted: 2 June 2020; Published online: 23 June 2020

\section{References}

1. Walsh, C. T. \& Wencewicz, T. A. Flavoenzymes: versatile catalysts in biosynthetic pathways. Nat. Prod. Rep. 30, 175-200 (2013).

2. Joosten, V. \& Van Berkel, W. J. H. Flavoenzymes. Curr. Opin. Chem. Biol. 11, 195-202 (2007).

3. Greening, C. et al. Physiology, biochemistry, and applications of $\mathrm{F}_{420}$ and FOdependent redox reactions. Microbiol. Mol. Biol. Rev. 80, 451-493 (2016).

4. Walsh, C. Naturally occurring 5-deazaflavin coenzymes: biological redox roles. Acc. Chem. Res. 19, 216-221 (1986). 
5. Hemmerich, P., Massey, V. \& Fenner, H. Flavin and 5-deazaflavin: a chemical evaluation of 'modified' flavoproteins with respect to the mechanisms of redox biocatalysis. FEBS Lett. 84, 5-21 (1977).

6. Megerle, U. et al. Unraveling the flavin-catalyzed photooxidation of benzylic alcohol with transient absorption spectroscopy from sub-pico- to microseconds. Phys. Chem. Chem. Phys. 13, 8869-8880 (2011).

7. Kutta, R. J., Archipowa, N. \& Scrutton, N. S. The sacrificial inactivation of the blue-light photosensor cryptochrome from Drosophila melanogaster. Phys. Chem. Chem. Phys. 20, 28767-28776 (2018).

8. Kutta, R. J., Archipowa, N., Johannissen, L. O., Jones, A. R. \& Scrutton, N. S. Vertebrate cryptochromes are vestigial flavoproteins. Sci. Rep. 7, 44906 (2017).

9. Massey, V. The chemical and biological versatility of riboflavin. Biochem. Soc. Trans. 28, 283-296 (2000).

10. Holtmann, D. \& Hollmann, F. The oxygen dilemma: a severe challenge for the application of monooxygenases? ChemBioChem 17, 1391-1398 (2016).

11. Insińska-Rak, M. \& Sikorski, M. Riboflavin interactions with oxygen-a survey from the photochemical perspective. Chem. Eur. J. 20, 15280-15291 (2014).

12. Gelalcha, F. G. Heterocyclic hydroperoxides in selective oxidations. Chem. Rev. 107, 3338-3361 (2007).

13. Gadda, G. Oxygen activation in flavoprotein oxidases: the importance of being positive. Biochemistry 51, 2662-2669 (2012).

14. Huijbers, M. M. E., Montersino, S., Westphal, A. H., Tischler, D. \& van Berkel, W. J. H. Flavin dependent monooxygenases. Arch. Biochem. Biophys. 544, 2-17 (2014).

15. Torres Pazmiño, D. E., Winkler, M., Glieder, A. \& Fraaije, M. W. Monooxygenases as biocatalysts: classification, mechanistic aspects and biotechnological applications. J. Biotechnol. 146, 9-24 (2010).

16. Zilly, F. E., Taglieber, A., Schulz, F., Hollmann, F. \& Reetz, M. T. Deazaflavins as mediators in light-driven cytochrome $\mathrm{P} 450$ catalyzed hydroxylations. Chem. Commun. 46, 7152-7154 (2009).

17. Su, Q., Boucher, P. A. \& Rokita, S. E. Conversion of a dehalogenase into a nitroreductase by swapping its flavin cofactor with a 5-deazaflavin analogue. Angew. Chem. Int. Ed. 56, 10862-10866 (2017).

18. Taglieber, A., Schulz, F., Hollmann, F., Rusek, M. \& Reetz, M. T. Light-driven biocatalytic oxidation and reduction reactions: scope and limitations. ChemBioChem 9, 565-572 (2008).

19. Duchstein, H.-J., Fenner, H., Hemmerich, P. \& Knappe, W.-R. (Photo) chemistry of 5-deazaflavin. Eur. J. Biochem. 95, 167-181 (1979).

20. Schmermund, L. et al. Photo-biocatalysis: biotransformations in the presence of light. ACS Catal. 9, 4115-4144 (2019).

21. Iwata, T. et al. Hydrogen bonding environments in the photocycle process around the flavin chromophore of the AppA-BLUF domain. J. Am. Chem. Soc. 140, 11982-11991 (2018).

22. Silva, E. \& Edwards, A. M. (eds) Flavins: Photochemistry and Photobiology (RSC Publishing, 2006).

23. Sancar, A. Mechanisms of DNA repair by photolyase and excision nuclease (Nobel Lecture). Angew. Chem. Int. Ed. 55, 8502-8527 (2016).

24. Sancar, A. Structure and function of DNA photolyase and cryptochrome bluelight photoreceptors. Chem. Rev. 103, 2203-2238 (2003).

25. Lee, J., Müller, F. \& Visser, A. J. W. G. The sensitized bioluminescence mechanism of bacterial luciferase. Photochem. Photobiol. 95, 679-704 (2019).

26. Conrad, K. S., Manahan, C. C. \& Crane, B. R. Photochemistry of flavoprotein light sensors. Nat. Chem. Biol. 10, 801 (2014).

27. Zollitsch, T. M. et al. Magnetically sensitive radical photochemistry of nonnatural flavoproteins. J. Am. Chem. Soc. 140, 8705-8713 (2018).

28. Cashmore, A. R., Jarillo, J. A., Wu, Y.-J. \& Liu, D. Cryptochromes: blue light receptors for plants and animals. Science 284, 760-765 (1999).

29. Kiontke, S., Gnau, P., Haselsberger, R., Batschauer, A. \& Essen, L.-O. Structural and evolutionary aspects of antenna chromophore usage by class II photolyases. J. Biol. Chem. 289, 19659-19669 (2014).

30. Lee, S. H., Choi, D. S., Kuk, S. K. \& Park, C. B. Photobiocatalysis: activating redox enzymes by direct or indirect transfer of photoinduced electrons. Angew. Chem. Int. Ed. 57, 7958-7985 (2018).

31. König, B., Kümmel, S., Svobodová, E. \& Cibulka, R. Flavin photocatalysis. Phys. Sci. Rev. 3, 1-17 (2018)

32. Metternich, J. B., Mudd, R. J. \& Gilmour, R. Science of Synthesis: Photocatalysis in Organic Synthesis, Vol. 1 (Thieme, 2018).

33. Zelenka, J., Cibulka, R. \& Roithová, J. Flavinium catalysed photooxidation: detection and characterization of elusive peroxyflavinium intermediates. Angew. Chem. Int. Ed. 58, 15412-15420 (2019).

34. Ramirez, N. P., König, B. \& Gonzalez-Gomez, J. C. Decarboxylative cyanation of aliphatic carboxylic acids via visible-light flavin photocatalysis. Org. Lett. 21, 1368-1373 (2019).

35. März, M. et al. Azodicarboxylate-free esterification with triphenylphosphine mediated by flavin and visible light: method development and stereoselectivity control. Org. Biomol. Chem. 16, 6809-6817 (2018).
36. Mühldorf, B. \& Wolf, R. C-H photooxygenation of alkyl benzenes catalyzed by riboflavin tetraacetate and a non-heme iron catalyst. Angew. Chem. Int. Ed. $\mathbf{5 5}$ 427-430 (2016).

37. Hering, T., Mühldorf, B., Wolf, R. \& König, B. Halogenase-inspired oxidative chlorination using flavin photocatalysis. Angew. Chem. Int. Ed. 55, 5342-5345 (2016).

38. Hartman, T. \& Cibulka, R. Photocatalytic systems with flavinium salts: from photolyase models to synthetic tool for cyclobutane ring opening. Org. Lett. 18, 3710-3713 (2016).

39. Mühldorf, B. \& Wolf, R. Photocatalytic benzylic C-H bond oxidation with a flavin scandium complex. Chem. Commun. 51, 8425-8428 (2015).

40. Mojr, V. et al. Tailoring flavins for visible light photocatalysis: organocatalytic $[2+2]$ cycloadditions mediated by a flavin derivative and visible light. Chem. Commun. 51, 12036-12039 (2015).

41. Feldmeier, C., Bartling, H., Magerl, K. \& Gschwind, R. M. LED-illuminated NMR studies of flavin-catalyzed photooxidations reveal solvent control of the electron-transfer mechanism. Angew. Chem. Int. Ed. 54, 1347-1351 (2015).

42. Metternich, J. B. \& Gilmour, R. A bio-inspired, catalytic $\mathrm{E} \rightarrow \mathrm{Z}$ isomerization of activated olefins. J. Am. Chem. Soc. 137, 11254-11257 (2015)

43. Zelenka, J. et al. Combining flavin photocatalysis and organocatalysis: metalfree aerobic oxidation of unactivated benzylic substrates. Org. Lett. 21, 114-119 (2019).

44. Zhang, W., Carpenter, K. L. \& Lin, S. Electrochemistry broadens the scope of flavin photocatalysis: photoelectrocatalytic oxidation of unactivated alcohols. Angew. Chem. Int. Ed. 59, 409-417 (2020).

45. Zhou, F., Li, R., Wang, X., Du, S. \& An, Z. Non-natural photoenzymatic controlled radical polymerization inspired by DNA photolyase. Angew. Chem. Int. Ed. 58, 9479-9484 (2019).

46. Link, P. A. J., van der Plas, H. C. \& Müller, F. Photoreduction of 5deazaflavins [1,3,9-triaza-anthracene-2(3H),4(10H)-diones]. J. Chem. Soc. Chem. Commun. 17, 1385-1387 (1986).

47. van Schie, M. M. C. H. et al. Deazaflavins as photocatalysts for the direct reductive regeneration of flavoenzymes. Mol. Catal. 452, 277-283 (2018).

48. Goldberg, M., Pecht, I., Kramer, H. E. A., Traber, R. \& Hemmerich, P. Structure and properties of 5-deazaflavin radicals as compared to natural flavosemiquinones. Biochim. Biophys. Acta 673, 570-593 (1981).

49. Shi, F. et al. A facile and efficient synthesis of novel pyrimido[5,4-b] $[4,7]$ phenanthroline-9,11(7H,8H,10H,12H)-dione derivativesviamicrowaveassisted multicomponent reactions. J. Heterocycl. Chem. 46, 563-566 (2009)

50. Khalafi-Nezhad, A., Sarikhani, S., Shahidzadeh, E. S. \& Panahi, F. l-Prolinepromoted three-component reaction of anilines, aldehydes and barbituric acids/malononitrile: regioselective synthesis of 5-arylpyrimido[4,5-b] quinoline-diones and 2-amino-4-arylquinoline-3-carbonitriles in water. Green Chem. 14, 2876-2884 (2012).

51. Edmondson, D. E., Barman, B. \& Tollin, G. Importance of the N-5 position in flavine coenzymes. Properties of free and protein-bound 5-deaza analogs. Biochemistry 11, 1133-1138 (1972).

52. Neumeier, M. et al. Dichromatic photocatalytic substitutions of aryl halides with a small organic dye. Chem. Eur. J. 24, 105-108 (2018).

53. Bardagi, J. I., Ghosh, I., Schmalzbauer, M., Ghosh, T. \& König, B. Anthraquinones as photoredox catalysts for the reductive activation of aryl halides. Eur. J. Org. Chem. 1, 34-40 (2018).

54. Ghosh, I. \& König, B. Chromoselctive photocatalysis: controlled bond activation through light-color regulation of redox potentials. Angew. Chem. Int. Ed. 55, 7676-7679 (2016).

55. Kim, H., Kim, H., Lambert, T. H. \& Lin, S. Reductive electrophotocatalysis: merging electricity and light to achieve extreme reduction potentials. J. Am. Chem. Soc. 142, 2087-2092 (2020).

56. Cowper, N. G. W., Chernowsky, C. P., Williams, O. P. \& Wickens, Z. K. Potent reductants via electron-primed photoredox catalysis: unlocking aryl chlorides for radical coupling. J. Am. Chem. Soc. 142, 2093-2099 (2020).

57. Ghosh, I., Ghosh, T., Bardagi, J. I. \& König, B. Reduction of aryl halides by consecutive visible light-induced electron transfer processes. Science $\mathbf{3 4 6}$ 725-728 (2014)

58. Meyer, A. U., Slanina, T., Heckel, A. \& König, B. Lanthanide ions coupled with photoinduced electron transfer generate strong reduction potentials from visible light. Chem. Eur. J. 23, 7900-7904 (2017).

59. Kerzig, C., Guo, X. \& Wenger, O. S. Unexpected hydrated electron source for preparative visible-light driven photoredox catalysis. J. Am. Chem. Soc. 141, 2122-2127 (2019).

60. MacKenzie, I. A. et al. Discovery and characterization of an acridine radical photoreductant. Nature 580, 76-80 (2020).

61. Cibulka, R. Strong chemical reducing agents produced by light. Nature $\mathbf{5 8 0}$, 31-32 (2020)

62. Kutta, R. J. Blitzlichtphotolyse - Untersuchung zu LOV-Domänen und Photochromen Systemen. Dissertation, Naturwissenschaftliche Fakultät IV -Chemie und Pharmazie- der Universität Regensburg (2012). 
63. Kutta, R. J., Langenbacher, T., Kensy, U. \& Dick, B. Setup and performance of a streak camera apparatus for transient absorption measurements in the ns to ms range. Appl. Phys. B 111, 203-216 (2013).

64. Baudisch, B. Time Resolved Broadband Spectroscopy from UV to NIR. Dissertation, Ludwig-Maximilians-Universität München (2018).

65. Lanzl, K., Sanden-Flohe, M. V., Kutta, R. J. \& Dick, B. Photoreaction of mutated LOV photoreceptor domains from Chlamydomonas reinhardtii with aliphatic mercaptans: implications for the mechanism of wild type LOV. Phys. Chem. Chem. Phys. 12, 6594-6604 (2010).

66. Granovsky, A. A. Firefly version 8. http://classic.chem.msu.su/gran/firefly/ index.html (1997).

67. Schmidt, M. W. et al. General atomic and molecular electronic structure system. J. Comput. Chem. 14, 1347-1363 (1993).

68. Neese, F. The ORCA program system. WIREs Comput. Mol. Sci. 2, 73-78 (2012).

69. Neese, F. Software update: the ORCA program system, version 4.0. WIREs Comput. Mol. Sci. 8, e1327 (2018).

70. Granovsky, A. A. Extended multi-configuration quasi-degenerate perturbation theory: the new approach to multi-state multi-reference perturbation theory. J. Chem. Phys. 134, 214113 (2011).

\section{Acknowledgements}

This project was supported by the Czech Science Foundation (project No 19-09064S), the Deutsche Forschungsgemeinschaft (KO 1537/18-1) and the European Research Council (ERC) under the European Union's Horizon 2020 research and innovation programme (grant agreement 741623). R.J.K. thanks the Deutsche Forschungsgemeinschaft for a Research Fellow stipend (KU 3190/1-1, KU 3190/2-1) supporting this project. The authors are grateful to Professor Eberhard Riedle (BioMolekulare Optik, Ludwig-MaximilliansUniversität München) for use of the ns to $\mu$ s transient absorption apparatus.

\section{Author contributions}

R.J.K., R.C., and A.G. wrote the paper with input from all of the authors. A.G. and T.N. performed the entire synthesis of all used compounds and conducted all photocatalytic dehalogenation reactions. A.G. did the electrochemical and EPR characterisation. R.J.K. together with A.G. and T.N. designed the spectro-electrochemistry experiment, which A. G. performed. R.J.K. together with A.G. and T.N. collected the stationary spectroscopic data. R.J.K. performed all time-resolved spectroscopic experiments and conducted the computational studies. Experimental data were analysed by R.J.K. together with A.G., computational data were analysed by R.J.K., and results were discussed by all authors. The project was conceived by R.C., R.J.K., and B.K.

\section{Competing interests}

The authors declare no competing interests.

\section{Additional information}

Supplementary information is available for this paper at https://doi.org/10.1038/s41467 020-16909-y.

Correspondence and requests for materials should be addressed to R.K., R.C. or B.K.

Peer review information Nature Communications thanks the anonymous reviewers for their contribution to the peer review of this work. Peer reviewer reports are available.

Reprints and permission information is available at http://www.nature.com/reprints

Publisher's note Springer Nature remains neutral with regard to jurisdictional claims in published maps and institutional affiliations.

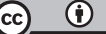

Open Access This article is licensed under a Creative Commons Attribution 4.0 International License, which permits use, sharing, adaptation, distribution and reproduction in any medium or format, as long as you give appropriate credit to the original author(s) and the source, provide a link to the Creative Commons license, and indicate if changes were made. The images or other third party material in this article are included in the article's Creative Commons license, unless indicated otherwise in a credit line to the material. If material is not included in the article's Creative Commons license and your intended use is not permitted by statutory regulation or exceeds the permitted use, you will need to obtain permission directly from the copyright holder. To view a copy of this license, visit http://creativecommons.org/ licenses/by/4.0/

(C) The Author(s) 2020 